\title{
Product Life Cycle: the evolution of a paradigm and literature review from 1950-2009
}

\author{
Hui Cao and Paul Folan \\ Department of Industrial Engineering, Tsinghua University, Beijing, China \\ (caohui@tsinghua.edu.cn)
}

Computer Integrated Manufacturing Research Unit (CIMRU), National University of Ireland, Galway, Galway, Ireland

(paul.folan@nuigalway.ie) 


\title{
Product Life Cycle: the evolution of a paradigm and literature review from 1950-2009
}

\begin{abstract}
Recently, Product Lifecycle Management (PLM) has become a popular topic in the academic literature. However, although it shares the same title, contemporary PLM is quite different from the early $20^{\text {th }}$ century's product lifecycle management culture, which was established upon the basis of the classical life cycle body of theory, which continued to be refined, right up to the end of 1960s. A comprehensive understanding of the creation and deployment of different strands of PLM strategy requires a knowledge of the basis of such paradigms - that is, the variety of product life cycle theories available to the researcher, and how these have come about. This paper reviews relevant product life cycle models presented historically in the literature and divides them into two categories - the long-established Marketing Product Life Cycle Model, and the emerging Engineering Product Life Cycle Model. An explanation of the former model leads to an understanding of its perceived shortcomings, and the reason for the take-up of later models. A correct knowledge of this is important, as contemporary PLM has been inundated with a variety of PLM methodologies and techniques, largely from the periodical literature and across the internet, often with no clear explication of the underlining product life cycle model used to derive the methodology. There is a need for analysis upon this issue; not just to clarify the mutable term "product life cycle", but for the provision of a correct understanding of the models that are informing the current debate, often outside academic circles.
\end{abstract}

Keywords: Marketing Product Life Cycle; Engineering Product Life Cycle Model

\section{Introduction}

Product Lifecycle Management (PLM) receives considerable attention from a wide range of academic disciplines, and from all aspects of the business community. Academic papers have appeared on the subject from the 1950s, while there is a huge 
volume of white papers, periodical articles, consultant's opinions, and vendor's advertisements that appear at regular intervals in trade publications, on internet websites, and across a plethora of other media forms - all of which confirms that PLM, if nothing else, is a subject of considerable popularity and a topic of heated debate in the casual and grey business literature. Among this paper's objectives is to plot briefly the contemporary development of the product life cycle concept from its initial beginnings in marketing, to its take-up by researchers in other fields, with a subsequent concentration upon the models of the product life cycle that are often unconsciously informing much of the popular debate on the subject of PLM. As will become clear from the discussion below, the product lifecycle concept can mean different things to different researchers, hence we must be careful to define its content and meaning here.

Before examining historical academic evidence, however, we may first address a word on the current practitioner literature, which is enjoying widespread popularity. Public perception of Product Lifecycle Management (PLM) has been driven by an extended marketing campaign on the part of many PLM interest groups that see PLM as an important business opportunity. In the periodical literature-including vendor white papers, grey literature, and internet forums sites dedicated to business solutions-we can see that it posits an optimistic future for a brand of PLM that remains essentially mechanistic in its origin.

In this view PLM development has really depended upon the idea of an evolution and continual assimilation of computer-oriented product-based solutions, from early engineering design applications (e.g. Computer Aided Design (CAD), or Computer Aided Manufacturing (CAM)) in the 1970s and 1980s, through to the integration of Enterprise Resource Planning (ERP), Customer Relationship Management (CRM), and Supply Chain Management (SCM) solutions in the early years of this century [Ameri and Dutta, 2005]. This evolution is depicted in Figure 1 after Ameri and Duttas' [2005] description of the same, and can stand very well for the form of PLM that influences the research of most of the existing PLM vendors currently in business. 


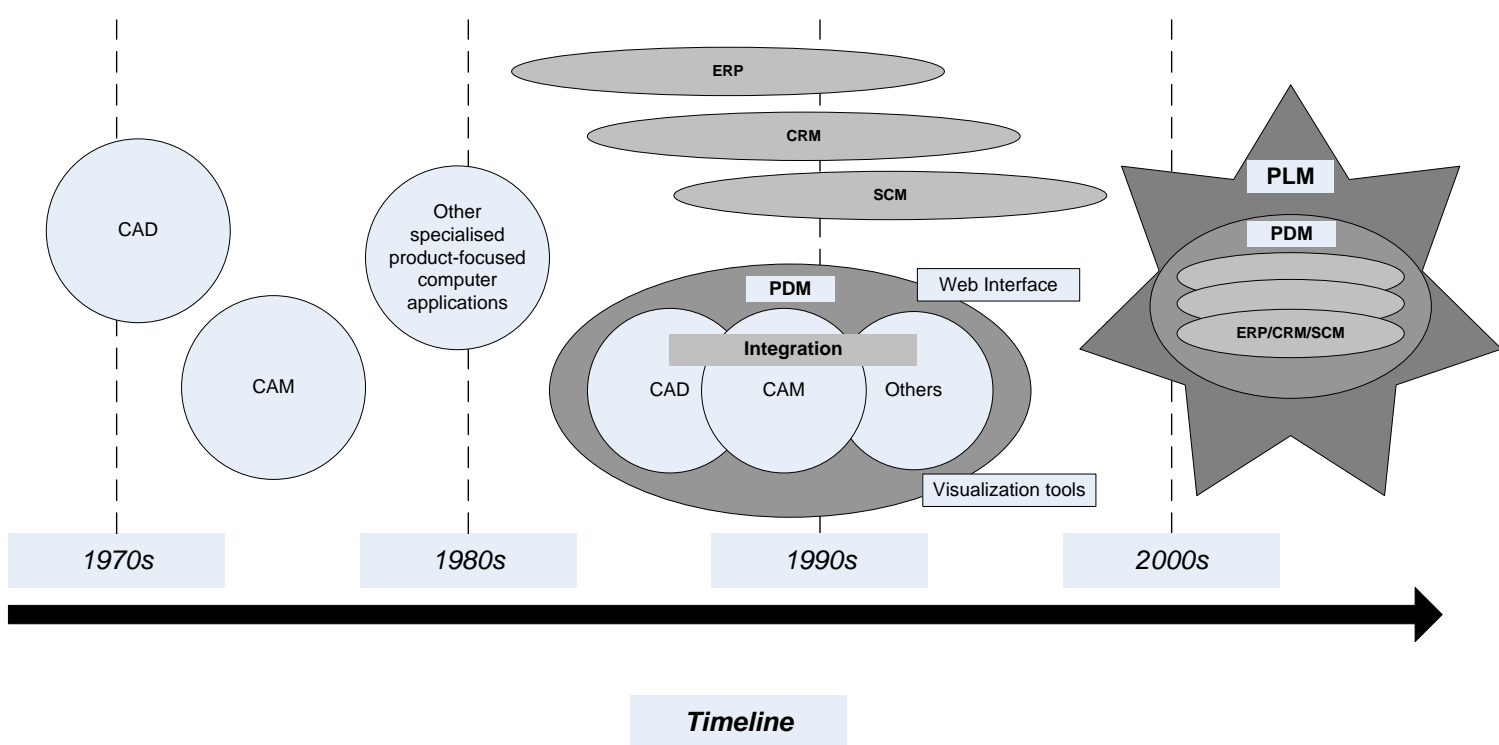

Figure 1: The development of PLM, described as an evolution of computing applications

In this figure we can see that the development of isolated computer applications, often for product design, were merged to form basic Product Data Management (PDM) systems in the 1980-90s, and then advanced by supplementing them with additional web and visibility tools; while the development of early PLM occurred with the incorporation of separate systems such as ERP, CRM and SCM into PDM in the new millennium- $\mathrm{a}$ process still continuing and being refined with additional supplementations today. Vendors have built their reputation on their ability to integrate these widely-varying systems into coherent, inter-organisational PLM solutions, while differentiation between them depends very much upon the variety of PLM "extras" that they can offer to their customers.

The theoretical reliance upon a mechanistic, computer-enabled, PLM infrastructure, as described in Figure 1 above, that subsumes all previously developed producttechnologies, cannot adequately address problems outside of its original remit-issues such as those examined by supply chain, extended enterprise and virtual enterprise researchers, for example. Instead, inhibiting factors upon PLM (such as unclear customer requirements, shorter delivery times and numerous technical constraints [Lee et al., 2006]; or those noted by Kim et al. [2006]: product data interoperability, system application interoperability, and process interoperability) may only be solved if a valuechain orientation is factored-in for our consideration. The major problem with the 
current vendor-oriented PLM remit, as described above, is that it cannot adequately handle such an additional value chain focus; instead, such a viewpoint must be tackled by the deployment of PLM concepts that have emerged from other viewpoints of the product lifecycle concept that is not dependent upon a simplistic examination of the emergence and merging of product-oriented computing tools in the past few decades.

If we turn to the initial research that propelled the term product lifecycle into the wider conciousness, we see that the concept centred around the need to produce a coherent framework that could account for the relative success or failure of an individual product introduced onto the market, when best to change strategies such as pricing [Dean, 1950] or product manufacture, and determining when a product should be discontinued [Kotler, 1965]. From these early studies a biologically-inspired life cycle of the product emerged that was divided into four phases (birth, growth, maturity, and decline), together with the familiar bell-shaped curve describing a simple parabola upon an axis of sales volume versus time [Levitt, 1965]. This theory was well-established by the 1960s, with sharp criticism of the approach first appeared in the 1970s. Concerns over the construct's validity when applied empirically, caused ambivalence towards the theory in the marketing environment in the long-term [Day, 1981].

The questioning has continued: products today have not remained a simple output of an individual organisation - who are free to delineate phases of 'life' for the product, such as introduction, growth, maturity and decline - as in the traditional product life cycle model; rather the validity of such a model has been questioned for the operation of today's companies in an inter-organizational context, and it may be criticised for its non-promotion of inter-connections between the phases involved, and its view of the product as having only a relatively finite existence. Contemporary research have moved beyond the one-of-a-kind product life cycle model with isolated phases of introduction, growth, maturity, and decline; instead the model must take into account, in a more explicit manner, the value chain itself, and be in some way part of its own regeneration.

Since the middle of the 1980s another type of product life cycle concept has emerged, and has been rigorously reviewed by many authors since its inception. This life cycle concept does not solely focuses on the market life of the product; instead, it examines the real and complete life of a single product - from product conception, through design, 
production, sale, customer use, and service, to, finally, decommissioning. The emergence of this model - which continues to use much of the same terminology that was initially introduced by the product life cycle, although very much in its own wayis a direct result of a continued interest in a biologically inspired 'life' ideology for the product under consideration. What has changed is the focus of the model, and its application.

The purpose of this paper is to provide clarity for the term 'product life cycle', and to chart its development from a marketing concept, to its wider emergence as a tool that is now used by an ever-broadening set of professionals-academics, researchers, consultants, vendors etc. The need for analysis upon this issue is necessary, not just to clarify the apparent mutability of the term-although this is important,- - but also to ensure the appropriate provision of a correct understanding of the models that are informing the current debate. This debate is emerging inside academic circles, where the relationship and use of so-called product life cycle models must be coherently related to previously conceived paradigms, resulting in a sharpening of both a conceptual awareness regarding what constitutes a product life cycle model and what doesn't, and also how such models may be legitimately applied. But the debate is also operating in a more unstructured fashion outside academic circles, fuelled by a plethora of grey literature and internet contributions, many positing their own form of the product life cycle. If the paradigm of the product life cycle is not to be damaged by this very ubiquity, then there is a need to consider periodically the evidence adduced for the major models that lie within its remit; and for an analysis of how, and why, multiple models appear to be informing separate debates, although there is a superficial commonality of terminology.

\section{Methodology}

The aim of this paper is to explicitly distinguish the 'product life cycle' theories, specifying the realm, models, usage, and state-of-the-art development for each type of the theories. As the theories are presented both in business and engineering domain, the EBSCO Business Source Premier Database is employed by us for searching the journal articles related to the concepts. Owing to the time and resource limits, we limited our explorations in the peer-reviewed papers that contain the keyword of "product life 
cycle" or "product lifecycle" in the title. Furthermore, the articles which are not available in full text in the database are ignored.

From the specified database a total of 118 records are retrieved using above criteria. Among the articles, 115 papers are identified for further examination, excluding one erratum and two other articles that are not directly related to the product life cycle theories discussed in this paper. Among the 115 articles, 77 articles merely discussed the traditional product life cycle model (M-PLC), and 37 articles purely follow the latter product life cycle concept (E-PLC); while the other article is related to both of the theory. Table 1 gives the number of articles published in each category by year. For a more reasonable analysis, the total number of articles available in the EBSCO Business Source Premier Database is also retrieved for comparison. The proportion of the articles identified to the total articles available is also shown in Table 1. Figure 2 and Figure 3 demonstrate the trends of the contributions over time more intuitively using column charts. The more detailed review of the two product life cycle categories will be given in the following two sections.

Table 1: Summary of the articles

\begin{tabular}{|c|c|c|c|c|c|c|}
\hline \multicolumn{2}{|c|}{ Year } & \multirow{2}{*}{$\begin{array}{c}\text { Total } \\
\text { Available }\end{array}$} & \multicolumn{2}{|c|}{ M-PLC Related } & \multicolumn{2}{|c|}{ E-PLC Related } \\
\hline From & To & & Number & Proportion (\%o) & Number & Proportion (\%) \\
\hline 1965 & 1967 & 20699 & 4 & 0.19 & 0 & 0.00 \\
\hline 1968 & 1970 & 22439 & 3 & 0.13 & 0 & 0.00 \\
\hline 1971 & 1973 & 25433 & 2 & 0.08 & 0 & 0.00 \\
\hline 1974 & 1976 & 32754 & 4 & 0.12 & 0 & 0.00 \\
\hline 1977 & 1979 & 37342 & 3 & 0.08 & 0 & 0.00 \\
\hline 1980 & 1982 & 39942 & 11 & 0.28 & 0 & 0.00 \\
\hline 1983 & 1985 & 41849 & 10 & 0.24 & 0 & 0.00 \\
\hline 1986 & 1988 & 42087 & 2 & 0.05 & 0 & 0.00 \\
\hline 1989 & 1991 & 54560 & 6 & 0.11 & 1 & 0.02 \\
\hline 1992 & 1994 & 67973 & 3 & 0.04 & 0 & 0.00 \\
\hline 1995 & 1997 & 88745 & 8 & 0.09 & 3 & 0.03 \\
\hline 1998 & 2000 & 109677 & 4 & 0.04 & 5 & 0.05 \\
\hline 2001 & 2003 & 129118 & 4 & 0.03 & 7 & 0.05 \\
\hline 2004 & 2006 & 152839 & 9 & 0.06 & 11 & 0.07 \\
\hline 2007 & 2009 & 114295 & 5 & 0.04 & 11 & 0.10 \\
\hline \multicolumn{2}{|c|}{ Summary } & 979752 & 78 & 0.08 & 38 & 0.04 \\
\hline
\end{tabular}




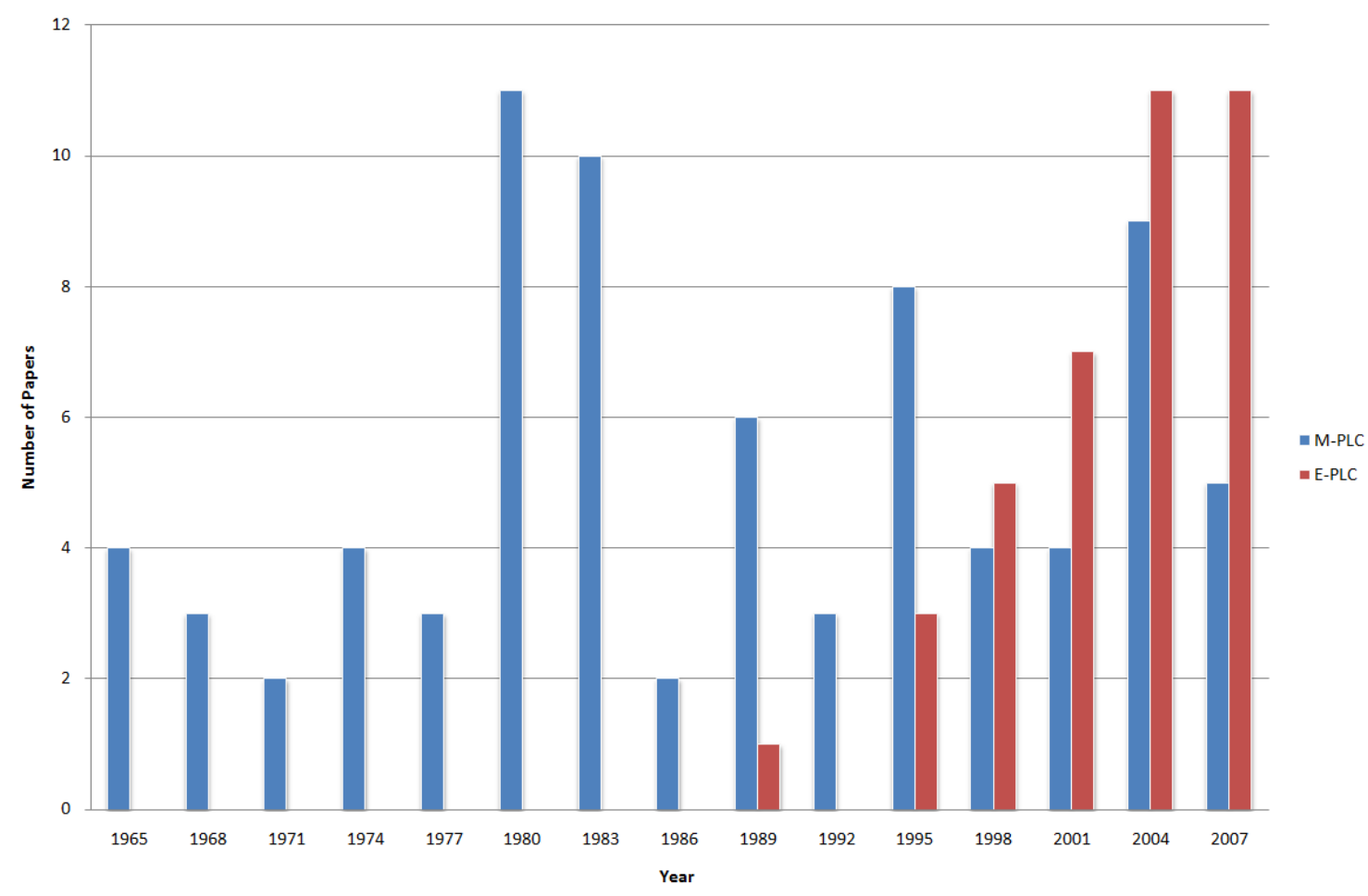

Figure 2: Number of contributions related to product life cycle theories

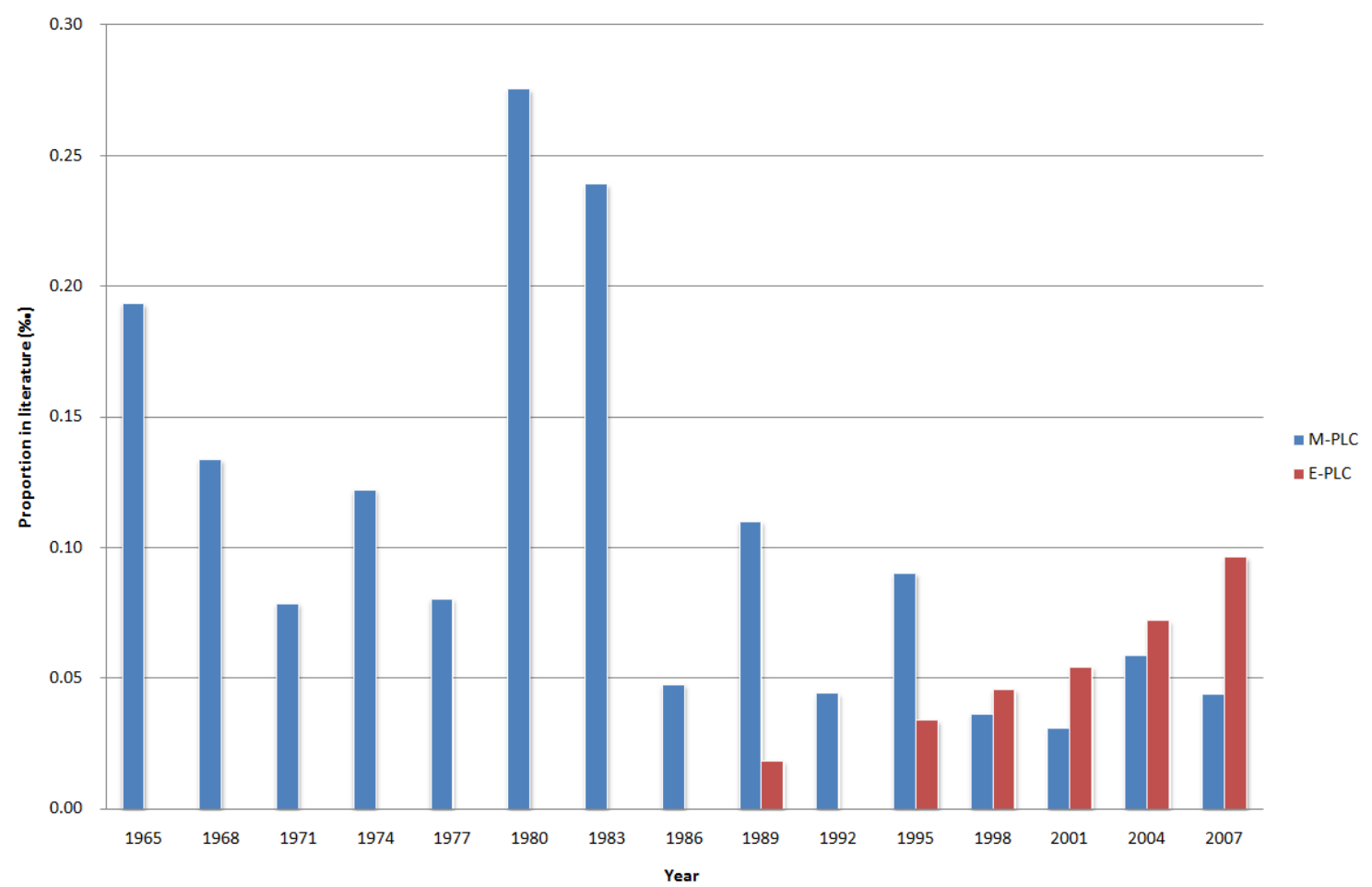

Figure 3: Proportion of contributions related to product life cycle theories 


\section{Marketing Product Life Cycle Model}

\subsection{Background}

The initial literature that heralds the beginning of product lifecycle analysis may be traced back to the 1950s, to the field of marketing. The first 'official' theory of the product lifecycle was firmly in place by the mid-1960s in marketing circles, and has continued to enjoy popularity, despite its age, with revivals of its original content occurring periodically. Equally, however, criticism of the original work-and thus its revival also - continues as a counterbalance to such literature.

Aside from this "initial" brand of the product lifecycle concept in marketing, the last 25 years or so has seen the development of a number of off-shoots to the original research that has allowed the concept to change from its initial conception in the marketing literature, to become the focus of attention in other research silos. This is the main delineation between the marketing product life cycle and the engineering product life cycle made here. The initial product lifecycle concept, although focused primarily upon marketing needs and conceptions, often strayed-off into regions that lay outside of the contemporaneous marketing purview, thus explaining its attraction for non-marketing researchers. As will become clear from the representative description of the product lifecycle, taken from Levitt [1965] and described below, the product lifecycle theory, once elaborated, tends to draw into its orbit a number of related fields not immediately open to the originators and which were, consequently, only elaborated later.

The marketing product life cycle germinated in the American atmosphere that existed following the Second World War. At that time the American economy was enjoying unparalleled success that was unmatched by Europe, depressed in the aftermath of war. Bennett and Cooper [1984] note two environmental factors that contributed to this: midcentury technological innovation; and vigourous market demand propelled by a growing population. Marketing research was dominated by this upsurge of economic prosperity which saw a huge growth in the number of product introductions, individual product growth and product successes or failures, as well as new product strategies for product placement and advertising, all catering for consumers that were increasingly demanding 
greater product choice following the lean war years.Explanations of the product life cycle theory can be traced back to Dean [1950], who studied the price policies for each phase of a product's market development. Dean believed that 'new products have a protected distinctiveness which is doomed to progressive degeneration from competitive inroads'; and this progress he called the 'cycle of competitive degeneration':

'The invention of a new marketable specialty is usually followed by a period of patent protection when markets are still hesitant and unexplored and when product design is fluid. Then comes a period of rapid expansion of sales as market acceptance is gained. Next the product becomes a target for competitive encroachment. New competitors enter the field, and innovations narrow the gap of distinctiveness between the product and its substitutes...' [Dean, 1950]

Although Dean only explored the pricing policies in the pioneering phase and the mature phase of a product's life cycle, his explanation of the cycle was explicit enough to be seen as the origin of the emerging product life cycle theory.

\subsection{Classical Product Life Cycle Theory}

Initially, the product lifecycle concept centred around the need to produce a coherent framework that could account for the relative success or failure of an individual product introduced onto the market, when best to change strategies such as pricing or product manufacture, and determining when a product should be discontinued. The proliferation of competition, and the increased number of brands individual companies were bringing to market, had made this job far more difficult than previously. Price-fixing of products at different levels of maturity was only one issue that was troubling the marketing research at the time; another was product obsolesce - the stage in a product's existence when it had outgrown its usefulness, or when the demand for its services was on the decline. Owing to the continual introduction and failure of new products into a viciously competitive market-place, product decline research was in abeyance, with many firms retaining product lines that had become obsolete without the appropriate steps towards retirement being taken. Theories for the appropriate phasing out of weaker products 
[Kotler, 1965] were in short supply, and would eventually become incorporated into the general theory of product lifecycles.

Eventually, by the end of the 1950s and throughout the following decade, the product lifecycle body of theory was emerging as an established entity in its own right, with the first promulgators and early influential papers including those by Forrester [1958], Patton [1959], Levitt [1965], Cox [1967], and Polli and Cook [1969]. In the first instance, the product lifecycle concept must have owed some of its adoption success to the high-profile publications that, throughout it earliest years, continued to revisit and promulgate its contents; these included the Harvard Business Review, and popular journals such as the Journal of Business. Practically speaking, the period ranging from the end of the 1950s to the mid-1970s were more about the promulgation of the theory, and combating its critics, than about any major empirical investigations of the theory in its own right. A later phase of empiricism would come in the late-1970s, and continues up to today, despite a vestige of the initial scepticism still being in evidence in the research.

The initial theory may now be outlined. As representative of this initial research we exhibit Levitt's conception in his Harvard Business Review paper "Exploit the product life cycle" in 1965; the main elements of this, and indeed the whole theory, are 
displayed in

\section{Box 1 \\ Product Lifecycle Theory after Levitt (1965)}

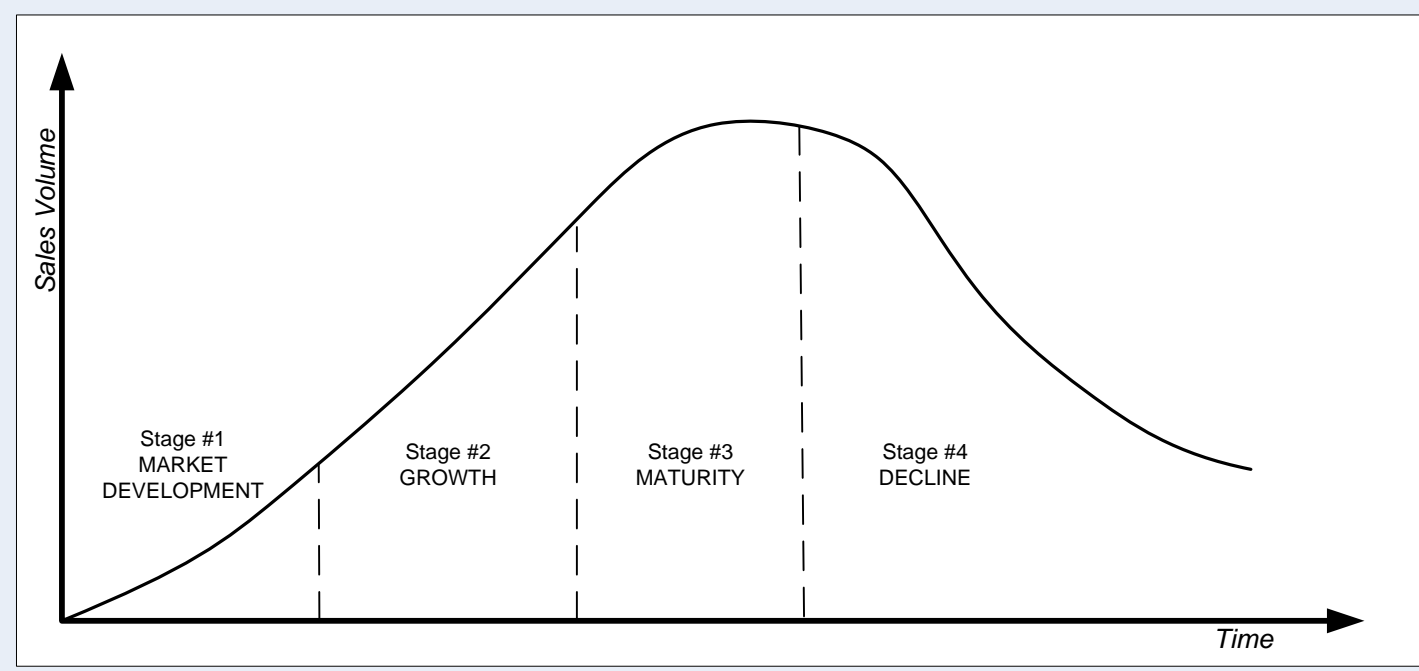

The life story of most successful products is a history of their passing through certain recognizable stages. These are (refer to figure):

Stage 1: Market Development-this is when a new product is first brought to market, before there is a proved demand for it, and often before it has been fully proved out technically in all respects. Sales are low and creep along slowly.

Bringing a new product to market is fraught with risks and unknowns; demand must be "created". There are a number of ravaging costs and frequent fatalities associated with launching new products; nothing takes more time, cost more money, involve more pitfalls, cause more anguish, or break more careers than new product programs. Therefore many firms avoid this stage, and will follow the innovator, who breaks the new ground. Many products fail and do not get past this stage; retailers and other sellers heavily relied upon to promote new products.

Stage 2: Market Growth-demand begins to accelerate and the size of the total market expands rapidly. It might also be called the "Takeoff Stage".

With a successful product there is a gradual rise in the sales curve. Potential competitors, who have been watching developments, launch competing products; product and brand differentiation begin to develop. The innovator must now switch from policies of trying to get customers to "try the product" in Stage 1, to "prefer his brand" over rivals; presence of competitors dictates and limits policies that can be used to achieve this. Increased sales results in opening new distribution channels, and even more competitors. Price undercutting begins to occur because of later advances in technology, production shortcuts etc.

Stage 3: Market Maturity-demand levels off and grows, for the most part, only at the replacement and newfamily formation rate.

Market saturation, both of innovator's and rival's brands; all sales prospects are full. Sales only grow on par with the population. Price competition becomes intense; finer and finer differentiations in the product and promotional and customer services, so as to achieve and hold brand preference. Retention of market niches important. Producer must hold his distribution outlets, retain shelf space, and try to secure more intensive distribution. Retailers' role reduced to that of merchandise-displayers.

Stage 4: Market Decline-the product begins to lose consumer appeal and sales drift downward.

Few companies able to weather the competitive storm. Overcapacity of product in the marketplace becomes epidemic. To hasten competitors' decline, some initiate depressive tactics: propose mergers/buy-outs, steep pricecutting etc. Production gets concentrated into fewer hands as more and more firms leave the competitive space, deeming it to be too unprofitable; prices and margins get depressed; consumers get bored with the product offering, revived only slightly by styling and fashion elements. Product declines to death or near-death.

Figure 4. Although even at this time there was some minute differences between the various authors in their explanations of the theory, these are practically insignificant and 
needn't detain us here; Levitt's [1965] version is representative and explains the concept well.

What is immediately contained in the explanation of the product lifecycle theory offered by Levitt [1965] in Figure 4 is a generic agenda for future product-related research to capture the ideals outlined in the notes that apply to each product lifecycle stage. Many of the elements discussed here, and by other practitioners stretching back to Dean [1950], would continue to occupy, and do occupy, the product-research space to the present day. The curve formed in the diagram - a simple parabola that can be represented by the equation [Cox, 1967]: $Y=a+b X+c X^{2}$; - is divided into four segments, not necessarily equidistant in terms of time, and named 1) market development, 2) growth, 3) maturity, and 4) decline; these divisions are agreed upon by all early commentators (later commentators felt free to add to this four-phase description of the product lifecycle (see, for example, Rink et al. [1999] who added a pre-lifecycle phase called "pioneering" just before introduction)). Each segment, or stage, has associated advice from whence the future research has drawn most of its impetus.

The key point of the division of the product's life into stages is that different strategies may be applied to a product class as it moves from one to another, thus allowing the product lifecycle to act as a basis for production planning and control [Forrester, 1958; Cox, 1967]. The metaphor of a product having a "life" is biological in origin [Dhalla and Yuspeh, 1976; Hayes and Wheelwright, 1979a], implying that the phases are fixed and non-negotiable. Although, even at the time of the original promulgation, initial empirical testing had meant that the theory could not be taken too seriously, "several writers have used the product lifecycle as a basis for recommendations about the content of marketing programs at different stages of the lifecycle" [Polli and Cook, 1969]; which meant, in effect, that despite its validity being suspect, the theory was gaining influence among marketers. The attraction of the theory to non-marketing specialists has already been noted, but this influence was to arrive later after the initial debate of the theory in marketing circles. The initial statement of the theory was followed by some not-very-extensive empirical work and a refutation of some of its basic contentions by opposing marketing researchers in the 1970s. 
We use the term Marketing Product Life Cycle (M-PLC) for this life cycle theory in the following parts of this paper. 


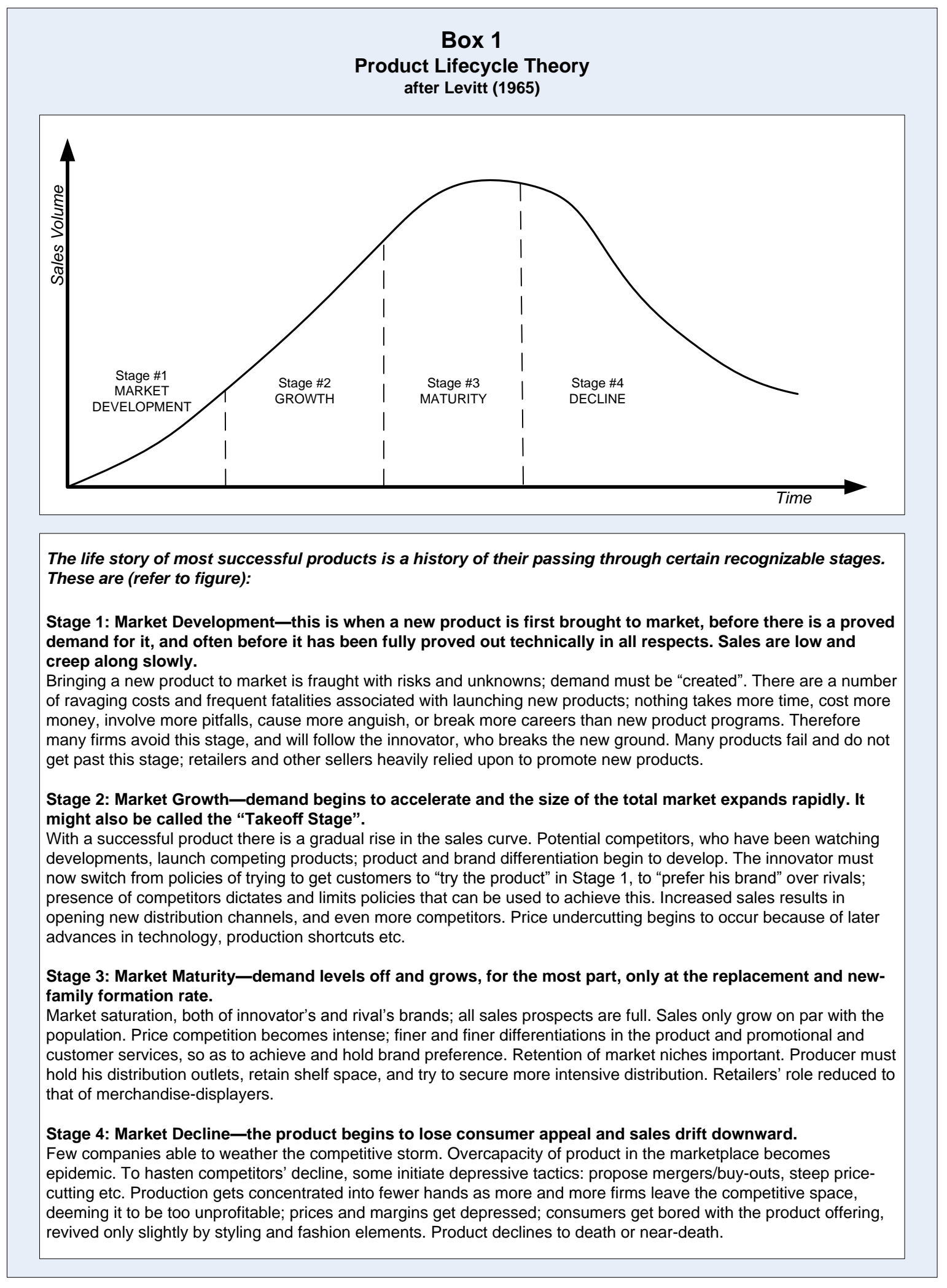

Figure 4: Product Life cycle Theory (adapted from Levitt [1965]) 
For examining the revolutionary path of the M-PLC theory, we identified the purpose of the $78 \mathrm{M}-\mathrm{PCL}$ related articles that we retrieved into seven categories (Table 2). After the theory was introduced (Introduction) to the public in 1960s, authors were engaged in quantitive validating the theory by empirically data (Validation), discussing the issues raised by the theory (Issues), and proposing their alternative patterns of the M-PLC model (Modification). The boom of the M-PLC theory took place in 1980s, when the theory was employed by researchers for analysis the business strategies in various situations (Usage), or extending the theory to other areas, e.g. international trade and religions (Extension). Till this stage, the M-PLC theory is considered to be well established and accepted by the majority. After the boom of a decade or so, the contributions to the M-PLC theory fell down to a moderate level from 1990s, or even a impoverished level considering its proportion to the total available articles in the database.

Table 2: Contributions to M-PLC

\begin{tabular}{|c|c|c|c|c|c|c|c|c|c|c|}
\hline \multicolumn{2}{|c|}{ Year } & \multicolumn{9}{|c|}{ M-PLC } \\
\hline From & To & Introduction & Validation & Issues & Modification & Usage & Extension & Other & Summary & $\%$ \\
\hline 1965 & 1967 & 2 & 1 & & & 1 & & & 4 & 0.19 \\
\hline 1968 & 1970 & & 1 & & 1 & & 1 & & 3 & 0.13 \\
\hline 1971 & 1973 & & & 1 & 1 & & & & 2 & 0.08 \\
\hline 1974 & 1976 & & & & & 2 & & 2 & 4 & 0.12 \\
\hline 1977 & 1979 & & 1 & & 1 & & 1 & & 3 & 0.08 \\
\hline 1980 & 1982 & & 2 & 1 & & 6 & 2 & & 11 & 0.28 \\
\hline 1983 & 1985 & & & 1 & & 7 & 2 & & 10 & 0.24 \\
\hline 1986 & 1988 & & & & & 2 & & & 2 & 0.05 \\
\hline 1989 & 1991 & & & 2 & & 1 & 3 & & 6 & 0.11 \\
\hline 1992 & 1994 & & 1 & & & 1 & 1 & & 3 & 0.04 \\
\hline 1995 & 1997 & & & & & 6 & 1 & 1 & 8 & 0.09 \\
\hline 1998 & 2000 & & & & & 4 & & & 4 & 0.04 \\
\hline 2001 & 2003 & & & & & 4 & & & 4 & 0.03 \\
\hline 2004 & 2006 & & & & & 7 & 1 & 1 & 9 & 0.06 \\
\hline 2007 & 2009 & & & & & 4 & 1 & & 5 & 0.04 \\
\hline Sumn & ary & 2 & 6 & 5 & 3 & 45 & 13 & 4 & 78 & 0.08 \\
\hline
\end{tabular}




\subsection{Challenges and Variations}

The key criticisms of this initial exposition of the product lifecycle theory may now be recounted. Dhalla and Yuspeh in their 1976 article 'Forget the product life cycle concept!' tackled a number of issues regarding the initial theory; their main criticisms are depicted in Table 1. These criticisms have had a direct result on the theory, particularly those related to product form and the fixed nature of the sequencing of the stages involved. It is generally allowed that the widely diverging empirical evidence collected since these criticisms were first made means that the product lifecycle theory cannot be applied in absolutist terms; rather, as Hayes and Wheelwright (1979a) concede, directly from Dhalla and Yuspehs' (1976) article:-

Irrespective of whether the product lifecycle pattern is a general rule or holds only for specific cases, it does provide a useful and provocative framework for thinking about the growth and development of a new product, a company, or an entire industry.

The authoritative ground, in the marketing sphere at least, has been conceded; the theory's inability to support itself by empirics, and the critical eye of Dhalla and Yuspeh [1976], have been sufficient to relegate, by the late 1970s and early 1980s, the original product lifecycle theory from its position as the cherished, dominant theory in marketing, to a more subordinate, supporting, "useful" role. Day [1981], for example, noted a contemporary ambivalence in marketing following such successful criticism, but still registered its popularity.

Currently, in marketing, this original theory is still sometimes deployed by those attracted to its simplicity. This, however, regularly induces the re-appearance of critical articles (see, for example, Grantham [1997]) to refute the more wilder claims made for the theory by these advocates.

Challenges have included queries into the inevitability of the sequences of the phases, criticisms of the vagueness ofborderlines betweenphases, and doubts about the difference between product class, product form and brand. These are discussed in briefly in the following paragraphs. 
The concept of M-PLC has been discussed for over half a century; however, the definition of a 'product' is still vague. Levitt [1965] suggest that the sales curve of the originator's brand usually does not form the same shape as the curve of the industry illustrated in

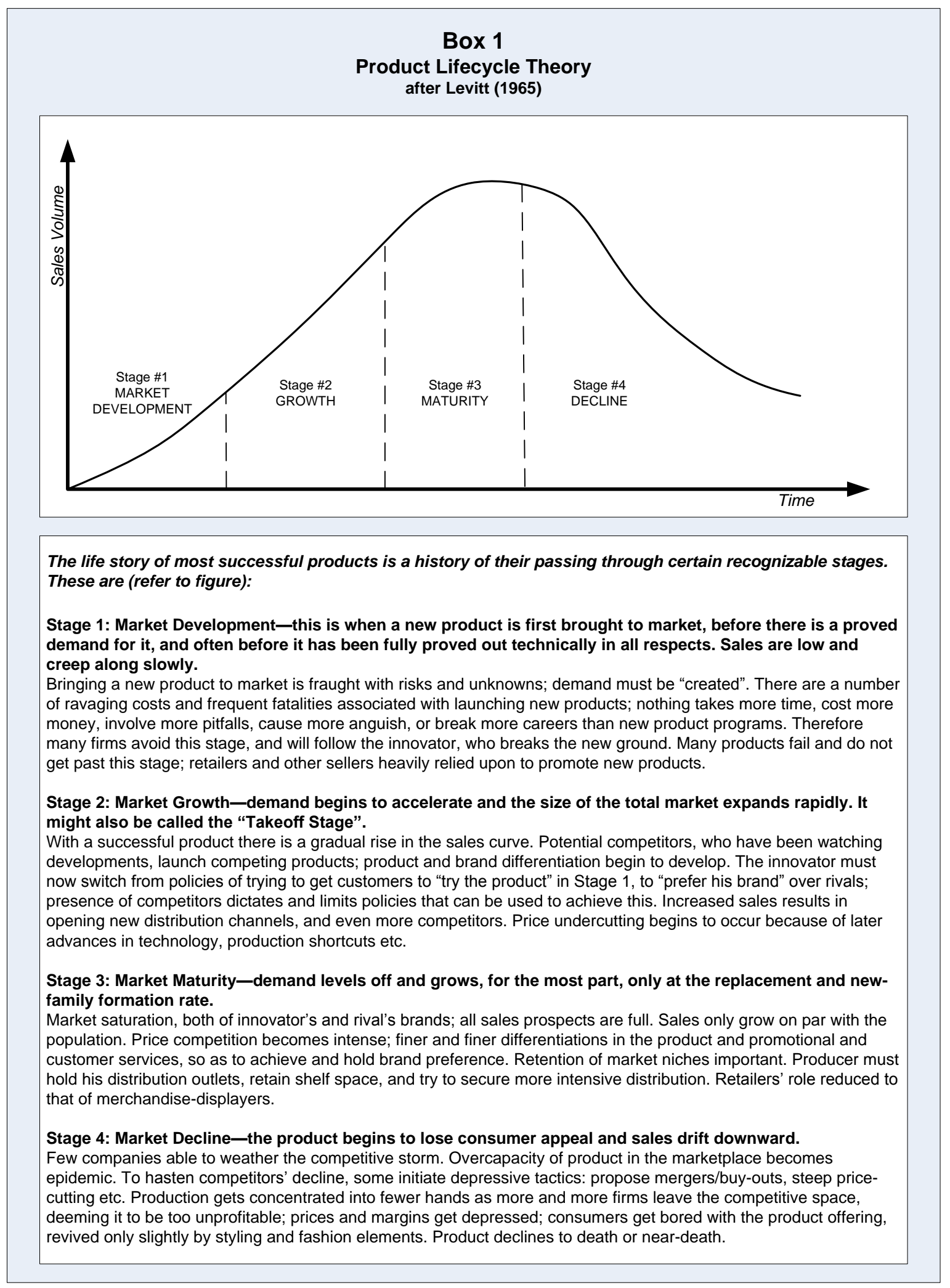


Figure 4. According to him, the 'product' in the M-PLC concept indicates the products of the whole industry, but not only a product brand. However, his meaning for the term 'industry' is unclear.The difference aggregation between product classes, product forms, and brands was first defined by Polli and Cook [1969]: items which belong in different product classes have near-zero demand cross-elasticity; all objects within a product form can be mean fully added in physical units; and brands within a product form are unique, apart from package differences. After a test of 140 products, including product classes, product forms, and brands, Polli and Cook [1969] concluded that the M-PLC model is a "good model", especially suitable for dealing with product forms.

However, a study carried by Dhalla and Yuspeh [1976] declared that only 17\% of the observed sequences in product classes and $20 \%$ of the sequences in product forms were significantly different from chance at the confidence of 99\%; and when it comes to brands, the M-PLC model has even less validity. In this case, the M-PLC model is doubted by a few authors on its usage of managing existing brands, which is usually the main task of a company.

Another major criticism on the M-PLC model is the identification of the four phases. The qualitative description of the phases has been recognised since 1950s; however, there are very few generic quantitative analyses on how to define the bounds of each phase.

Table 3 gives two examples of quantitative distinction of the M-PLC phases. Cox [1967] introduced two measures of product life-catalogue life and commercial life-to determine the M-PLC phases in the investigation of the ethical-drug industry in the United States.

While Polli and Cook [1969] established a distribution of percentage changes in sales to identify the phases. On the assumption that distribution follows the normal function with mean zero, Polli and Cook considered that the percentage changes lower than $-\sigma / 2$ represent significant 'declines'; values greater than $+\sigma / 2$ represent significant 'growth'; while values in the range of $\pm \sigma / 2$ correspond to the 'maturity' phase. 
Table 3: Examples of criteria for phases

\begin{tabular}{lll}
\hline \multicolumn{1}{c}{ Phases } & \multicolumn{1}{c}{ Cox [1967] } & Polli and Cook [1969] \\
\hline Introduction & Up to five thousand new prescriptions in a single month & $S_{i}$ less than 5\% of peak sales \\
Growth & From five thousand new prescriptions in a single month & $S_{i}{ }^{*}$ greater than +.05 \\
Maturity & From maximum monthly revenue & $S_{i}{ }^{*}$ in the +.05 to -.05 range \\
Decline & Below 20\% or 10\% of maximum monthly revenue & $S_{i}{ }^{*}$ greater than -.05 \\
\hline$S_{i}=$ Yearly sales of nondurable $i$ divided by sales of all nondurables \\
$S_{i}{ }^{*}=$ Yearly percentage changes in $S_{i}$
\end{tabular}

Despite the above-mentioned definitions, there are few contributions on the quantitative identification of the M-PLC phases. Owing to a lack of well-testified phase identification methods, a few authors, including Wood [1990] and Grantham [1997], concluded that the model is useful to monitor sales but is limited in forecasting. The value of the M-PLC model then is limited to foreseeing the next phase of the market and working backwards [Levitt, 1965] using qualitative analysis.

\subsection{Alternative Stages and Patterns}

Regardless of the widely acceptance of the M-PLC theory, the dividing of the life cycle stages and the pattern of the life cycle curve is never unified. In the articles we examined, there are 32 papers explicitly presented the life cycle stages they employed; 15 papers employed the popular four-stage version described above (introduction, growth, maturity, and decline), while others had their own opinion. Some added a pioneering stage at the beginning, some inserted a saturation stage between maturity and decline, and some engaged the early-growth and late-growth stages instead of the maturity and decline stages.

Furthermore, some authors asserted that not every product goes through all the four stages of the M-PLC, e.g. the decline stage may not occur in some situation, or the sales volume collapses suddenly at some point of the growth stage. There are also two authors divided the M-PLC into introductory-growth and maturity-decline stages, owing to the vagueness of the borders between the stages. Moreover, some authors proposed that the product's life may become resuscitation again after a period of decline and thus a "second curve" begins. 
Corresponding to the various dividing of M-PLC stages, the patterns of the M-PLC curve also varied from the dominance of the parabolic M-PLC curve illustrated in Figure 4 Error! Reference source not found. in the M-PLC literature, variations of the curve are proposed by several researchers. Cox [1967] described the follwing curve forms when revenue $(Y)$ is plotted against time $(X)$, with aggregation parameters denoted by $a, b, c, d$ and $e$ :

- $\quad$ Type 1: $Y=a+b X+c X^{2}$

- Type 2: $Y=a+b X$ (where $b$ is positive)

- $\quad$ Type 3: $Y=a+b X$ (where $b$ is negative)

- Type 4: $Y=a+b X$ (where $b$ is zero)

- $\quad$ Type 5: $Y=a+b X+c X^{2}+d X^{3}$

- $\quad$ Type 6: $Y=a+b X+c X^{2}+d X^{3}+e X^{4}$

Cox found that curve types 1,2 , and 5 may evolve into curve type 6 which can be considered as the basic M-PLC curve in the ethical-drug industry he studied. Corresponding to this, Levitt [1965] also believed that the life cycle can be managed and extended by promotion or other sales strategies. Furthermore, according to Wood [1990], Meenaghan and O'Sullivan attempted to consolidate the situation and presented some alternative patterns of the variant curve shape in their discussion of shape and length of M-PLC.

\subsection{New Issues for M-PLC}

Owing to rapid changes in production and marketing environments in recent decades, various forms of collaborative networks have come into force, and the definition of the word 'product' as term has become more elastic. Latter-day concerns for the M-PLC theory are listed below: 
1. Considering an extended product, which is served by a variety of enterprises along the value chain, the M-PLC model depicts the life cycle of the production/sale process of the product (usually from the point of view of just one frim), with no consideration for the viewpoints of other businesses along the value chain? Are there also 'design life cycle', 'service life cycle', and 'decommission life cycle' models existing for other collaboration network partners to manage their business? If so, are there any connections or interactions among these models?

2. Due to eco-regulations and economic benefits, the demanufacturing of a product or component becomes more favourable and even essential to a value chain. When these refurbished or remanufactured products enter the market, how should the MPLC model describe these second-hand products? Do they pose a threat to the primary route of the product, from birth to decline?

3. Furthermore, since the product is mass customised and varies one with another, how should the word 'product'be exactly defined? Even if the difference aggregation between product classes, product forms, and brands is still valid in mass customisation, the theory of M-PLC will be less valuable in the management of mass customised production, owing to its poor reliability on detailed forecasting.

4. On the other hand, more and more technology-driven companies, such as Intel, are benefiting from time-pacing innovations, a strategy for competing in fast-changing, unpredictable markets by scheduling change at predictable time intervals [Eisenhardt and Brown 1998]. Time-pacing introduces products according to a prearranged schedule, or a pre-determined development rhythm (Lagenevik et al., 2003); it tackles the central concept of 'introduction' in the classic M-PLC model, whereby product introduction is generally based upon demand characteristics of the existing market, and where it does not attempt to synchronise product introduction as with time-pacing, which effectively trys to set-up as an 'internal metronome' reflecting the marketplace inside the organization. Time-pacing changes the concept of product introduction, which in turn alters the way that the product may be viewed and condisered through its product life. 


\section{Engineering Product Life Cycle}

The original product life cycle model traditionally resided within the marketing arena. However, for the concept to develop, a focus beyond marketing became a prerequisite; this led to different formations of the product lifecycle theory emerging outside of marketing, as non-marketing practitioners took the concept up, and applied it to their own research strands. Much of the associated advice in, for example, Levitt's [1965] description of the market product life cycle, strayed outside of the contemporareous marketing purview; so much so, in fact, that an explicitly non-marketing focus became important if the concept was to retain its relevance. Current product offerings were not the simple output of an individual organisation - with traditionally delineated phases of 'life', such as introduction, growth, maturity and decline, as in the traditional M-PLC model; rather the validity of this a model was being reconsidered in the light of the operation of today's companies, with the subsequent emergence of criticisim of the MPLC's non-promotion of inter-connections between the phases involved, and its view of the product as having only a relatively finite existence. Contemporary research was to move beyond the one-of-a-kind product life cycle model with isolated phases of introduction, growth, maturity, and decline, as mentioned previously; instead the model was to take into account, in a more explicit manner, the value chain itself, and be in some way part of its own regeneration.

Instances of this change of direction began to emerge in the mid-1960s, and had solidified into a new sphere of development for product life cycle research by the 1970s. As early as 1966 the initial concept of the product lifecycle had evolved a politicized, "international" dimension in the work of Vernon [1966], who originated the concept of the "international product lifecycle" — a theory that exploits economic/locational factors to explain the movement and evolution of new product technology diffusion across national boundaries. Here the focus of the lifecycle had moved beyond the simple requirements of the product itself, to include its processes also, and then posits a lifecycle from initial "advanced" countries to final "less developed" countries.

Elsewhere Hayes and Wheelwright [1979a, b] were beginning to examine the link between the process and the product lifecycle. They describe a 'product-process matrix' 
with product structure on the $\mathrm{x}$-axis, and process structure on the $\mathrm{y}$-axis. Mapped onto this structure in a diagonal line, thus matching each $\mathrm{x}$-axis type against its corresponding $\mathrm{y}$-axis type, were typical company positions that are characterised by each product/process mapping; those companies who seek a position 'off the diagonal' were seeking a competitive advantage [Hayes and Wheelwright, 1979a, b]. The meaning of this new framework was intentionally strategic in focus: Hayes and Wheelwright developed 'a framework that can help a company to conduct a diagnosis of its strategic evolution, think creatively about possible future strategic directions, and explicitly involve both marketing and manufacturing in coordinating and implementing its competitive goals' [Hayes and Wheelwright, 1979b]. Effectively they tied the concept of the product lifecycle into its associated process lifecycle and used this combination to formulate strategy. By so doing, they explicitly free the product lifecycle concept from an exclusively marketing orientation, and apply a corresponding process lifecycle structure to form their matrix framework. Here strategic management subordinates the 'product life' to its need to find a coherent company strategy; in the marketing literature, the product lifecycle concept was elevated to an end in itself, with strategies being sought to satisfy its requirements.

This difference of approach was to be repeated throughout other research silos as time went on, with the product lifecycle theory, its terminology or even its underpinning precepts, undergoing subordination to whatever elements happen to be dominant in the research field under discussion. Space is insufficient to document all of these variations, but mention may be made of the following: Bennett and Coopers' [1984] business life cycle; Potts' [1988] service life cycle; and the emergence of research upon life cycle assessment, which is documented further below in the development of the E-PLC.

Since the middle of the 1980s, another type of product life cycle concept has raised the researchers' attention and has been rigorously reviewed by many authors since its inception. This life cycle concept does not solely focuses on the market life of the product; instead, it examines the real and complete life of a single product-from product conception, through design, production, sale, customer use, and service, to, finally, decommissioning. In order to distinguish these emerging models from the established M-PLC models, these all-embracing models are referred to as Engineering Product Life Cycle (E-PLC) models. 


\subsection{Emergence of the E-PLC}

Research on the E-PLC originated with the development of life cycle costing (LCC) and life cycle assessment (LCA). LCC was initiated by the US Department of Defence (DoD) in the early 1960s to increase the effectiveness of government procurement [Asiedu and $\mathrm{Gu}, 1998$ ]. Stimulated by findings that operation and support costs for a typical weapon system accounted for $75 \%$ of the total cost, the DoD developed LCC analysis as a framework for specifying the estimated total incremental costs of developing, producing, using, and retiring a particular item [Asiedu and Gu, 1998].

In the meantime, LCA was developed from the already existing substance flow analysis in the late 1960s and early 1970s; it is a methodology for assessing the environmental impacts and resource consumption associated with the existence of products from cradle to grave [Westkaemper et al., 2001a].

The concepts of LCC and LCA both quietly evolved throughout the 1970s. With the advent of a range of Computer-Aided design, Manufacturing and Engineering (CAD/CAM/CAE) tools in 1980s, the introduction of innovative products entered a new era. In establishing the earlier computer integrated manufacturing (CIM) vision, it was found necessary to integrate design and manufacturing, which has resulted in terms such as 'design for manufacture', 'design for production', and 'design for assembly' etc. [Alting, 1993]; however, little attention was paid to the usage or disposal/recycling phases.

In the mid 1980s, measures on packaging and packaging-waste-management were introduced in many European countries by the EU directive 85/339/EEC. Since then, LCA and LCC has experienced a revival, and associated research has emerged to cope with the rapid extension of environmental concerns, and the resultant change in competitive circumstances that this has fostered. Meanwhile, additional approachese.g. 'design for service', 'design for disassembly', and 'design for recycling'-were introduced into the 'design for $\mathrm{X}$ ' (DfX) realm. Subsequently, Life Cycle 
Design/Engineering was explored when researchers (see for example,Alting [1993; 1995]; and Ishii [1994]) tried to integrate these disparate DfX methodologies.

In parallel with the development of CAX (Computer Aided Design/Engineering/etc.) tools, Product Data Management (PDM) systems appeared to centralise product information-created by various information authoring tools-into a single, authoritative database. Over time, with the integration of new functionalities, such as change management, document management, workflow management and project management into PDM categories, PDM systems held the promise of providing both for concurrent engineering and streamlined product development processes, within the enterprise, and across the extended enterprise, when enabled by web technologies [Ameri and Dutta, 2005].

Supported by the above-mentioned methodologies, contemporary E-PLC, based on PLM (Product Lifecycle Management), emerged as a combination of academic research and commercial exploitation of organisational applications [Cao et al., 2007]. Figure 5 gives a sketch of the contemporary E-PLC related research, as suggested by Westkämper [2001a].

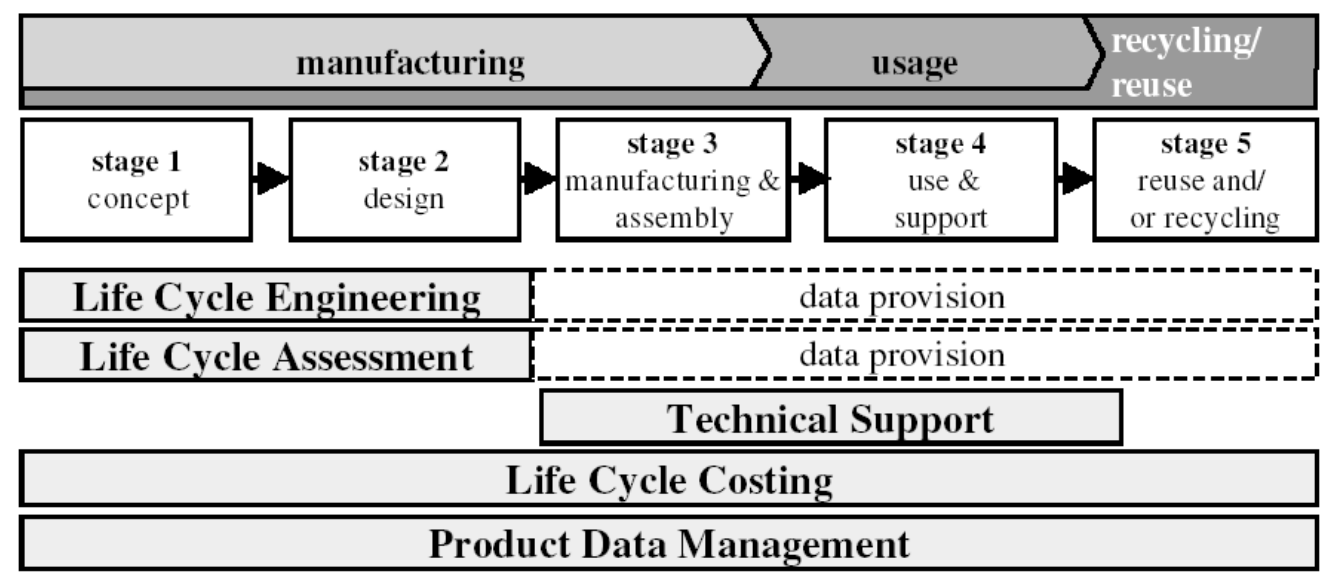

Figure 5: Applications of E-PLC Management [Westkaemper et al., 2001a]

Upon an examination of the research that has emerged that has principally focused upon the E-PLC model, foundational studies in life cycle analysis remain prevalent. In the 38 E-PLC related articles we reviewed, the most popular topic is LCC and LCA 
(categorised as Evaluation in Table 4). The second most popular is the presentation of IT technologies for collecting life cycle data and assisting E-PLC management (IT). The other popular topics include life cycle design/modelling (Engineering), and recycling/reuse tactics (EOL, end-of-life) etc. This collection of topics appears to have explored the E-PLC from the technology/engineering perspective, which is the reason why we categorise them as theEngineering Product Life Cycle. Table 4 gives the number of the papers we identified in each category. The first E-PLC related paper that we retrieved from the EBSCO database was published at the end of 1980s. Since then, it shows a steady increase both in the number and the proportion to the total available articles in the database.

Table 4: Contributions to E-PLC

\begin{tabular}{|c|c|c|c|c|c|c|c|c|c|c|}
\hline \multicolumn{2}{|c|}{ Year } & \multicolumn{7}{|c|}{ E-PLC } & \multirow[b]{2}{*}{ Summary } & \multirow[b]{2}{*}{$\%$} \\
\hline From & To & Introduction & Evaluation & Engineering & MOL & EOL & IT & Other & & \\
\hline 1965 & 1967 & & & & & & & & 0 & \\
\hline 1968 & 1970 & & & & & & & & 0 & \\
\hline 1971 & 1973 & & & & & & & & 0 & \\
\hline 1974 & 1976 & & & & & & & & 0 & \\
\hline 1977 & 1979 & & & & & & & & 0 & \\
\hline 1980 & 1982 & & & & & & & & 0 & \\
\hline 1983 & 1985 & & & & & & & & 0 & \\
\hline 1986 & 1988 & & & & & & & & 0 & \\
\hline 1989 & 1991 & 1 & & & & & & & 1 & 0.02 \\
\hline 1992 & 1994 & & & & & & & & 0 & 0.00 \\
\hline 1995 & 1997 & & 1 & & 1 & & & 1 & 3 & 0.03 \\
\hline 1998 & 2000 & & 1 & 1 & & 1 & 1 & 1 & 5 & 0.05 \\
\hline 2001 & 2003 & & 2 & 3 & & & 2 & & 7 & 0.05 \\
\hline 2004 & 2006 & & 5 & 1 & & 1 & 2 & 2 & 11 & 0.07 \\
\hline 2007 & 2009 & 1 & 1 & 1 & & 3 & 4 & 1 & 11 & 0.10 \\
\hline Sum & mary & 2 & 10 & 6 & 1 & 5 & 9 & 5 & 38 & 0.04 \\
\hline
\end{tabular}

\subsection{Contemporary Perspectives of E-PLC}

The E-PLC model involves the study of the complete life of a product-from cradle to grave, from product conception, through design, production, sale, customer use, and service, to decommissioning. Currently there is no standardised E-PLC model 
available - a consequence of researchers in particular research fields investigating PLC elements in relative isolation from each other; however, a number of E-PLC perspectives have been proposed in the last two decades, with one of the most fundamental elements of these models being the consistent reliance upon the same leading publications. Design, Production, Customer Usage and End-of-life decommissioning are common phases in the E-PLC models suggested by these authors, and these are described below in general.

From the point of view of product design, a six-phase life cycle (needs recognition, design/development, production, distribution, usage, and disposal/recycling) is suggested by Alting [1993], who believes that all six phases which a product goes through have to be considered at the conceptual stage.

Additionly, and also based on life cycle design, Ishii et al. [1994] introduced a 'material life cycle' concept (Figure 6.b) extended from their product life cycle vision (Figure 6.a). Material life cycle analysis was addressed by them to assess the residual value of a material when recycled under a certain scenario.

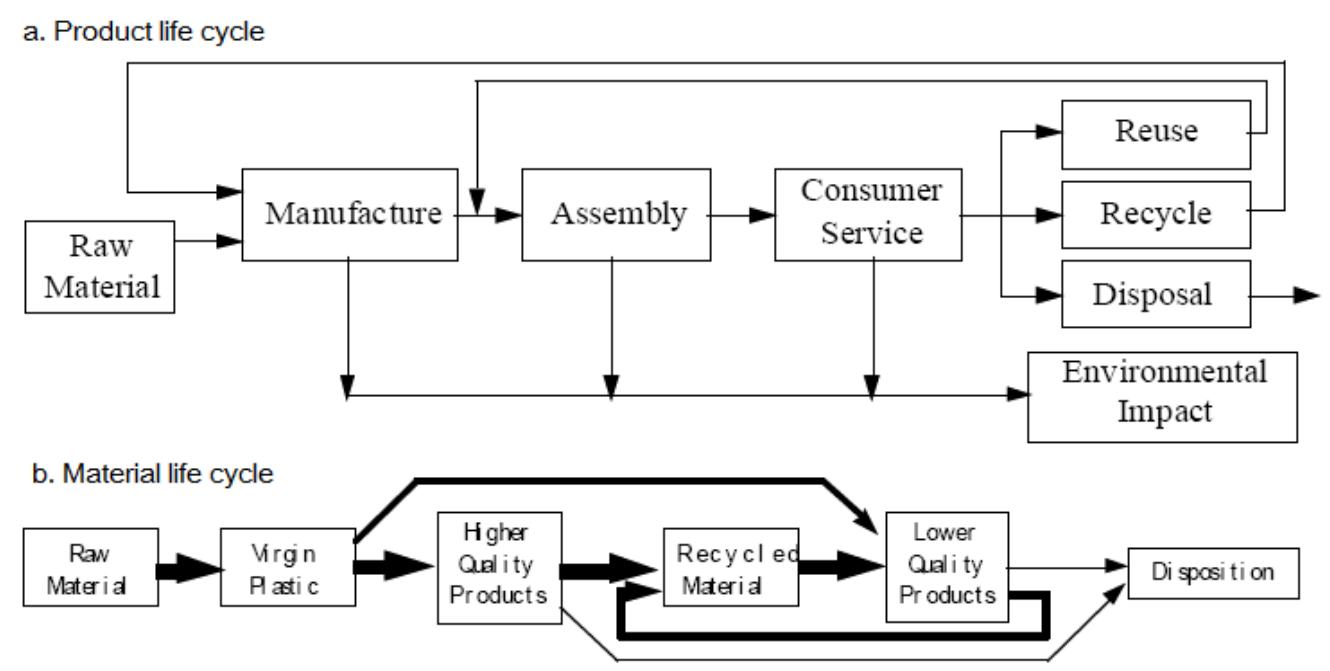

Figure 6: Product life cycle and material life cycle by Ishii et al. [1994]

The product life cycle model proposed by Ishii et al. [1994] was further adapted by Asiedu and $\mathrm{Gu}$ [1998]. The remanufacture process was introduced and a connection between disposal and the environmental impact was amended (Figure 7). Nevertheless, in their analysis of product life cycle cost, Asiedu and Gu [1998] distinguish between only four phases: design development, production, use, and disposal. Meanwhile, 
WestKämper [2001b] included five phases (concept, design, manufacturing and assembly, use and support, reuse and/or recycling) in their analysis of LCC and LCA.

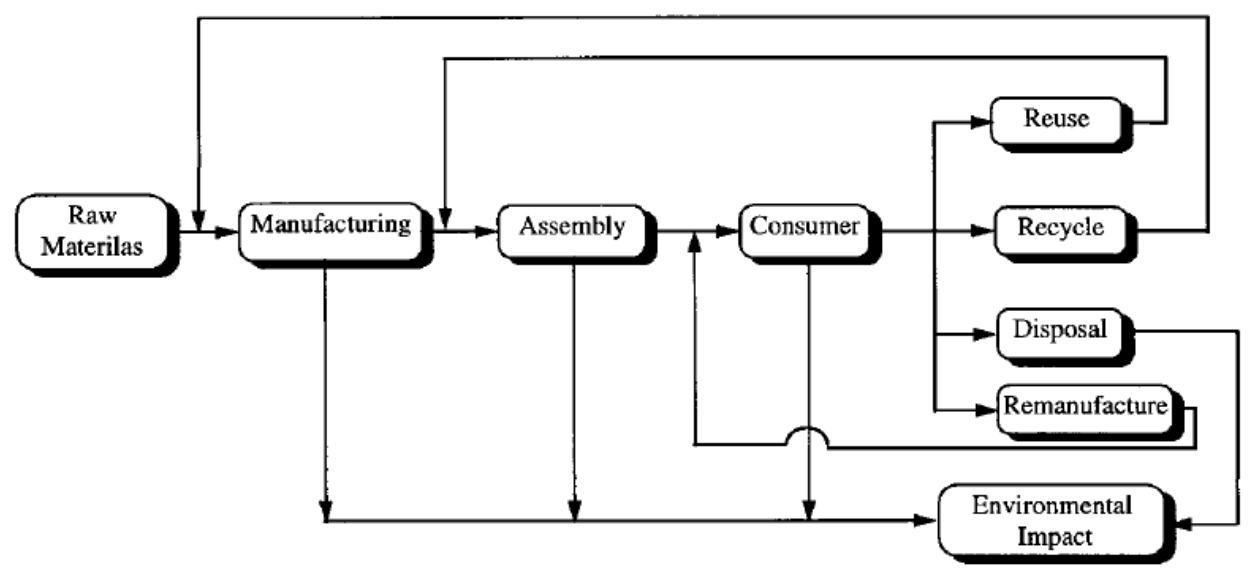

Figure 7: Product life cycle adapted by Asiedu and Gu [1998]

Furthermore, a System Life Cycle was introduced by Kriwet et al. [1995] that integrated product life cycle design. Accordingly, the system here includes a life cycle of three elements: the product, its related processes, and its logistic support (Figure 8); these three life cycles should be considered simultaneously when following the system life cycle during the acquisition, utilisation, and recycling phases [Kriwet et al., 1995].

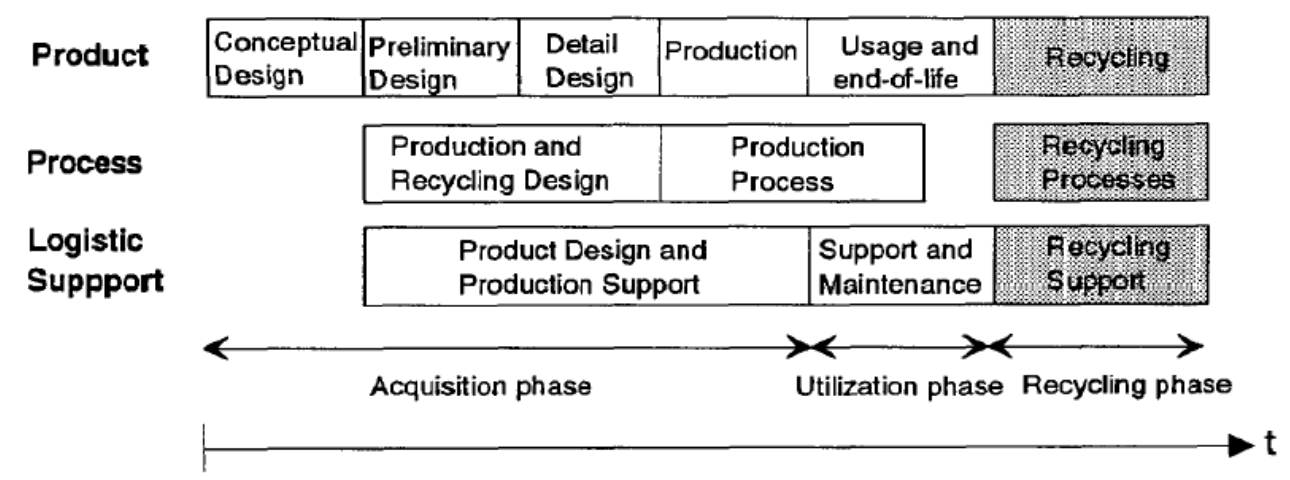

Figure 8: Product, Process, and Support Life Cycles suggested by Kriwet et al. [1995]

Figure 9 illustrates a recently developed generic E-PLC model, which follows the model generically outlined by Kiritsis et al. [2003]. The contemporary vision utilised in this model tightly couples both material and information flows at the product's design and manufacturing stages (called the beginning-of-life (BOL) phase). A second phase follows, where the finished product is purchased by the customer and is used and repaired when necessary (called the middle-of-life (MOL) phase) - this phase decouples 
the information flow from the material flow and returns information to BOL as required. In a final phase the customer has completed their use of the product and this, in turn, is released for decommissioning (called the end-of-life (EOL) phase); here the final decoupling of the material and information flows first forged in BOL is made and material and components are returned to BOL and MOL, while information flows return useful maintenance information to MOL, and design and manufacturing information to BOL. This product lifecycle model becomes a closed-loop of continuous improvement, with flows from BOL to MOL and EOL and back again, allowing product designers in BOL to introduce ever-improved products to the market; with the added possibility of improving the existing product in the field by the provision of value chain services as and when it is deemed expedient. This E-PLC model, being most sophisticated produced yet, is described in more detail in the following sub-sections, according to its leading phses, BOL, MOL, and EOL.

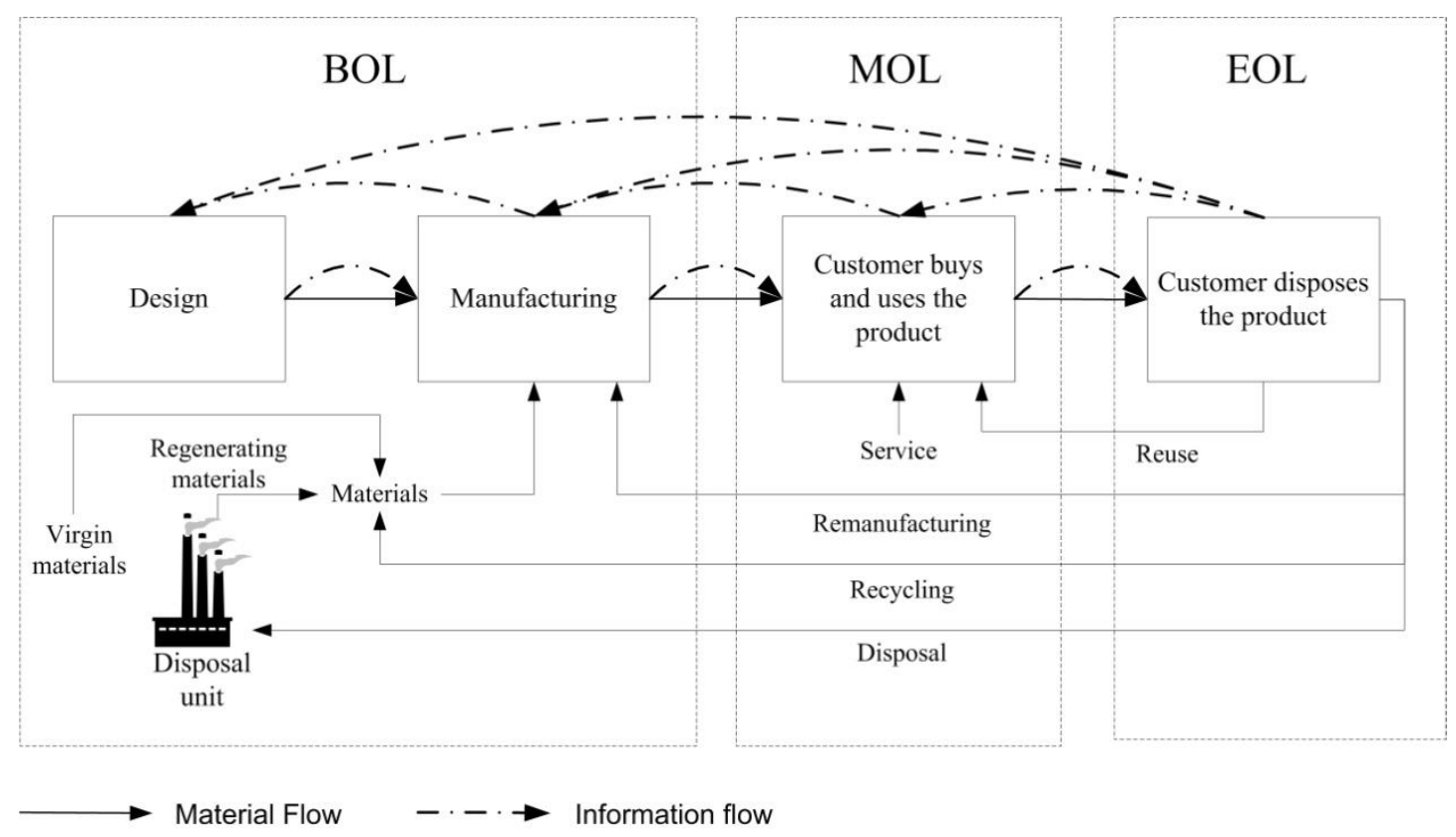

Figure 9: Closed loop E-PLC perspective

\subsubsection{Beginning-of-Life}

BOL is the phase where the product concept is generated and its physical model is realized. The activities included in this phase contain product conception, preliminary and detailed design, manufacturing and assembly, and may include some initial distribution to the consumer. 
As the product design stage determines $70 \%$ of the product cost [Lee et al., 2006](a figure that may rise to $85 \%$, according to research by Asiedu and Gu [1998]), the BOL phase is critical in the E-PLC. In the closed-loop E-PLC, as in the figure above, designers and producers will receive feedback with detailed information from distributors, maintenance/service engineers, or customers on product usage, conditions of retirement, and the disposal of their products. Therefore, they will be able to exploit the expertise and know-how of the other players in the E-PLC. It will improve the quality of future product designs and the efficiency of production processes put in place to produce these designs.

\subsubsection{Middle-of-Life}

MOL is the phase where products are distributed, used, maintained, and serviced by customers or engineers. MOL activities include distribution, maintenance/service, spare parts management, hotline/enquiries, training, inspections, preventive maintenance, repairs, and usage/operation.

The MOL phase of a product expands the value-added processes after the delivery of the product to the customer; indeed, this phase of the life cycle is experiencing rapid growth as its importance becomes increasingly recognised. After-sales market sizes in the auto-, computer-, and telecommunication-industries in 1994 were 90, 16.4 and 15.8 billion dollars respectively [Cohen and Whang, 1997]. Further, it is reported that up to $30 \%$ of the funds quota of the German mechanical engineering industry results from after-sales service [Westkaemper et al., 2001b]; while Cohen and Whang [1997] has argued that in some industries — including construction equipment, elevators, main frame computers, and automobiles - the profit margin for the provision of service parts and after-sales services far exceeds the margin on the sale of the product itself.

\subsubsection{End-of-Life}

Legislation related to EOL product management has proliferated over the past decade both in the EU and in the US. Governments require manufacturers in many industries, including automotive and electronic industries, to take the responsibility for their products' EOL processing under programmes such as the extended producer responsibly scheme [Bellmann and Khare, 2000]. EOL is the phase where products that have lost 
their usage value are collected, disassembled, refurbished, reassembled, recycled, reused, or disposed. EOL starts from the time when the product no longer satisfies the initial purchaser [Rose et al., 2002]; then the product is collected to Materials Recover Facilities (MRF) for reprocessing.

According to de Brito and Dekker [2004], reprocessing can occur at different levels: product level (repair), module level (refurbishing), component level (remanufacturing), selective part level (retrieval), material level (recycling), and energy level (incineration). Furthermore, as can be seen from Figure 9, a variety of material return flows exist from EOL, depending upon final component quality; these include: reuse components (to MOL); remanufactured components (retooled to original quality levels and reused in $\mathrm{BOL}$ ); recycled materials (base materials-not components; back to BOL); and disposables from which some useful base materials may yet be retained [Thierry et al., 1995]. The detailed description of these processes are listed below [adapted from Parlikad et al., 2003]:

- Repair and reuse: simply correction of specified faults in a product to return the used products in working order. Generally, the quality of the repaired products is inferior to those of remanufactured and reconditioned alternatives.

- Refurbishing/Recondition: to bring the quality of used products up to a specified level by disassembly to the module level, inspection and replacement of broken modules. Refurbishing could also involve technology upgrading by replacing outdated modules or components with technologically superior ones.

- Remanufacturing: to bring used products up to quality standards that are as rigorous as those for new products by complete disassembly down to the component level and extensive inspection and replacement of broken/outdated parts.

- Cannibalisation: to recover a relatively small number of reusable parts and modules from the used products, to be used in any of the three operations mentioned above.

- Recycling, to reuse materials from used products and parts by various separation processes and reusing them in the production of the original or other products. 
- Shredding, to reduce material size to facilitate sorting. The shredded material is separated using techniques based on magnetic, density or other properties of the materials.

- Incineration: incinerate the product for energy recovery.

- Disposal, to landfill the product without energy recovery.

\section{Relationships between M-PCL and E-PLC}

Although M-PLC and E-PLC bear the same name-Product Life Cycle-in the reviewed literature, they were developed separately, and consequently have different models, methods and intentions. Thus they should be distinguished more explicitly:

- M-PLC is developed from a macro view of the production business, and the life cycle describes the business life of one product type/brand. On the other hand, E-PLC is developed with a focus on the micro view of a product, and the life cycle in E-PLC describes the life activities of an individual product.

- M-PLC usually focuses on the physical product and serves as a tool for forecasting and managing the marketing strategy for the producer; while E-PLC focuses on the extended product [Thoben et al., 2001], which combines intangible services with the tangible product.

- Traditional M-PLC is tended by the producer itself, making it effectively intraorganisational in nature; while E-PLC is managed by the extended enterprise, and collaboration in the extended enterprise is crucial to the E-PLC management.

- Information in M-PLC is dedicated to the specific product type/brand, and this information has very limited usage in the next generation of the product; while the information in E-PLC forms 'improving' loops, and continuously supports the development of a new generation of products.

Despite their differences, however, the research and management of M-PLC and E-PLC should not be isolated. The management of E-PLC can derive benefits from the research on M-PLC of the product, as the products that appear from different phases of the MPLC will experience a different E-PLC route: 
- The products sold in the introduction phase of M-PLC may be owned by fashion-driven customers. They may be willing to purchase these products, although expensive, and the product may be discarded relatively quickly when a replacement item is introduced. In this case, the product will experience a shorter first-hand lifespan and may still have good have sufficient resource recovery value in the EOL phase, particularly for reuse.

- The products sold in the growth phase of M-PLC may have flaws in design and manufacturing, thus they may require more servicing than a product sold in its mature phase. Buyers of this phase's products may hold the product longer than buyers at the introduction phase, thus products sold in the growth phase may be discarded with a quality suitable for remanufacturing in the EOL phase.

- In the decline phase of the M-PLC, the reused/refurbished/remanufactured products may take-up a considerable portion of the market. These products are usually cheap and the servicing of these second-hand products may be a problem owing to the availability of spare parts etc.

On the other hand, information collected in the management of the E-PLC can also benefit research of the M-PLC by the provision of critical information on the service and decommission businesses of the product. This information should raise the accuracy of the prediction of M-PLC phases.

\section{Conclusion}

By the end of the 1960s, the M-PLC theory was well established and validated. According to the theory, most successful products in the market passed through four recognisable phases: development, growth, maturity, and decline. Each of these four phases required different business strategies to maximise the product's profitability, and the purpose of the M-PLC model was to fit the product's marketing status into established phases and then to choose the best business strategies for competitive purposes.

Despite significant criticism, this classical model has shown remarkable resilence in the past five decades, withthe M-PLC theory becoming a core element in the marking arena. 
However, critiques have continued to appear. These challenges include queries regarding the inevitability of the sequences of the phases, criticisms concerning the borderlines between the phases, and doubts about differentiating between product class, product form and brand.

Since the birth of the theory in 1950, relatively few changes have been brought to the model. However, the circumstances of business and production have change considerably since its inception. The dynamic nature of the business environment today has forced enterprises to work together and engage in a variety of inter-organisational infrastructures, e.g. extended enterprises and virtual enterprises, to transform simple products into extended products, and hence to improve their competitiveness. The pace of product-oriented innovations has increased drastically too, owing to the emergence and wide diffusion of high-technology applications, forcing companies to challenge existing viewpoints about once-stable product conceptions. Moreover, stricter ecoregulations, together with the rapid inflation in the price of virgin materials, has had the consequent effect of pushing enterprises towards a focus upon end-of-life product decommission, and subsequent resource recovery.

These changes have brought more issues to the M-PLC model, especially when it is used with the extended product. In the mean time, a new definition of the "product life cycle' was being adopted by many researchers, who examined the behaviour of products from a much more 'micro' view, by means of contemporary ICTs. This model is called the Engineering Product Life Cycle (E-PLC) by us here, for explanation purposes.

Distinguishing itself from previous M-PLC models, E-PLC is developed with a focus on the micro view of a product, i.e. the life cycle in E-PLC describes the life activities of an individual clone of a particular product. Focusing on the extend product instead of the physical product, E-PLC is usually managed by the extended enterprise, a value-chain conception, which may, or may-not, be led by the prime firm-or Original Equipment Manufacturer (OEM).

E-PLC models involve the complete life of a product - from cradle to grave, from product conception, through design, production, sale, customer use, and service, to 
decommissioning. With a research basis both in life cycle analysis and interorganisational modelling, coupled with an appropriation of some earlier M-PLC model terminology, thecontemporary vision utilised in this model tightly couples both material and information flows at the product's design and manufacturing stages (BOL); proceeding to a second phase where the product has emerged and is purchased by the customer and is used and repaired when necessary (MOL) - this phase decouples the information flow from the material flow and returns information to BOL as necessary. In a final phase the customer has completed their use of the product and this, in turn, is released for decommissioning (EOL); here the final decoupling of the material and information flows first forged in BOL is made and material and components are returned to $\mathrm{BOL}$ and $\mathrm{MOL}$, while information flows return useful maintenance information to MOL, and design and manufacturing information to BOL.

The environmental attributes of a product are largely fixed in its BOL phase; however, owing to a lack of information and heterogeneous product returns, production planning and control encounters more difficulty in the EOL business. The performance of the EOL business is usually limited by these uncertainties.

The E-PLC based Product Lifecycle Management has emerged, in the last decade or so, as the most sustained approach towards the management of the product both inside the four walls of the company, and further afield, in the company's value chain. By managing the product throughout the whole value chain, uncertainties are expected to diminish owing to the availability of information related to the whole E-PLC activity.

So much for the theory; for successful deployment of the E-PLC model, however, a number of issues remain to be tackled, including:

\section{1) Product lifecycle information integration}

For managing a product throughout its life span, the availability of product information along its whole value chain is crucial. TodayHowever, today the information flow generally breaks down after the delivery of the product to the customer, and becomes less and less complete from the usage/service phase to the final decommission scenario. 
With product embedded information devices (e.g., Radia Frequcency Identification (RFID) tags), it is possible to capture usage information automatically and share product related information/knowledge with others in the value chain. The availability of product related information from the MOL phase, for example from the service realm, will facilitate the widespread emergence of continuous-imporovement services, such as predictive maintenance. The implementation of such a system requires a high level of inter-organizational informationsharing, with an attendant information infrastructure in place, and an agreed set of cooperation policies amongst value chain partners, whilst technical and political issues may remain to be resolved in real-time.

\section{2) Issues of security and privacy}

Once E-PLC information is integrated and shared throughout the whole value chain, security and privacy issues become an issue. Here security is responsible for the full or partial access, or denial of access, to the collected life cycle data by authorised and unautnorised parties. The creation of privacy policies prevent the information system collecting information which the holders don't want other parties to receive. This is fairly crucial in the E-PLC management; in the contemporary business environment competition is between value chains, and it is common that one company is involved in several value chains which compete with each other. There are risks that one company's private information is unveiled to its competitors by the third party while involved in EPLC management activities. Similarly, product consumers may have fears over how collected data may be used or misused (e.g. vehicle owners may not want others to know where they have been). So it is important to specify policies related to the collection and usage of information, such as (1) what information can be retrieved; (2) who can access the retrieved information; and (3) where the information can be used. These must be agreed across the PLM value chain.

3) Product lifecycle management service

In a trend that appears to be emerging globally on the back of concerns over issues regarding the environment, the product's manufacturer is required to take more responsibilty for their products in the service and demanufacturing stages. However, the service/demanufacturing of product is often carried out by a third partner. In this case, both of the manufacturer and the third partner suffer from a lack of the product 
information - a significant barrier that inhibits the take-up of extended producer responsibilities by the manufacturer.

In this regard, a service opportunity exists. A product lifecycle management service can help to make product related information available to all the organisations along a product's value chain. Thus, the producer can track the product throughout its lifetime, while logistics/service/demanufacturing partners can access appropriate design and manufacturing information easily. This service may be hosted by a third party service provider beyond the value chain via existing or relatively inexpensive technologies (e.g. company intranets, web browsers etc.): an option which should be attractive to SMEs and non-dedicated service personnel.

\section{References}

Alting, L. (1993). Life-cycle design of products: a new opportunity for manufacturing enterprises. In A. Kusiak (Ed.), Concurrent Engineering: Automation, Tools, and Techniques (pp. 1-17). New York: Wiley.

Alting, L. (1995). Life Cycle Engineering and Design. CIRP Annals - Manufacturing Technology, 44(2), 569-580.

Ameri, F., \& Dutta, D. (2005). Product lifecycle management: closing the knowledge loops. Computer-Aided Design \& Applications, 2(5), 577-590.

Asiedu, Y., \& Gu, P. (1998). Product life cycle cost analysis: state of the art review. International Journal of Production Research, 36(4), 883-908.

Bellmann, K., \& Khare, A. (2000). Economic issues in recycling end-of-life vehicles. Technovation, 20(12), 677-690.

Bennett, R. C., \& Cooper, R. G. (1984). The Product Life Cycle Trap. Business Horizons, 27(5), 7.

Cao, H., Folan, P., Masocolo, J., \& Browne, J. (2007). RFID in product lifecycle management: a case in the automotive industry. International Journal of Computer Integrated Manufacturing, In Press, Corrected Proof.

Cohen, M. A., \& Whang, S. (1997). Competing in product and service: A product life-cycle model. Management Science, 43(4), 535. 
Cox, W. E., Jr. (1967). Product Life Cycles as Marketing Models. The Journal of Business, 40(4), 375-384.

Day, G. S. (1981). THE PRODUCT LIFE CYCLE: ANALYSIS AND APPLICATIONS ISSUES. Journal of Marketing, 45(4), 60-67.

de Brito, M. P., \& Dekker, R. (2004). A Framework for Reverse Logistics. In R. Dekker, M. Fleischmann, K. Inderfurth \& L. N. V. Wassenhove (Eds.), Reverse Logistics: Quantitative Models for Closed-Loop Supply Chains (pp. 3-28): Springer.

Dean, J. (1950). Pricing Policies for New Products. Harvard Business Review, 28(6), 45-53.

Dhalla, N. K., \& Yuspeh, S. (1976). Forget the product life cycle concept! Harvard Business Review, 54(1), 102-112.

Eisenhardt, K. M. and S. L. Brown (1998). TIME PACING: COMPETING IN MARKETS THAT WON'T STAND STILL. Harvard Business Review 76(2): 59-69.

Forrester, J. W. (1958). Industrial dynamics. Harvard Business Review, 36(4), 37-66.

Grantham, L. M. (1997). The validity of the product life cycle in the high-tech industry. Marketing Intelligence \& Planning, 15(1), 4-10.

Hashimoto, K. (2003). Product life cycle theory: a quantitative application for casino courses in higher education. Hospitality Management, 22(2), 177-195.

Hayes, R. H., \& Wheelwright, S. C. (1979a). The dynamics of process-product life cycles. Harvard Business Review, March-April, 127-136.

Hayes, R. H., \& Wheelwright, S. C. (1979b). Link manufacturing process and product life cycles. Harvard Business Review, January-February, 133-140.

Ishii, K., Eubanks, C. F., \& Di Marco, P. (1994). Design for product retirement and material lifecycle. Materials \& Design, 15(4), 225-233.

Kim, H., Kim, H. S., Lee, J. H., Jung, J. M., Lee, J. Y., \& Do, N. C. (2006). A framework for sharing product information across enterprises. International Journal of Advanced Manufacturing Technology, 27, 610-618.

Kiritsis, D., Bufardi, A. and Xirouchakis, P., Research issues on product lifecycle management and information tracking using smart embedded systems. Advanced Engineering Informatics, 2003, 17 (3-4), 189-202.

Kotler, P. (1965). Phasing out weak products. Harvard Business Review, March-April, 170-187. 
Kriwet, A., Zussman, E., \& Seliger, G. (1995). Systematic integration of design-for-recycling into product design. International Journal of Production Economics, 38(1), 15-22.

Lee, C. K. M., Ho, G. T. S., Lau, H. C. W., \& Yu, K. M. (2006). A dynamic information schema for supporting product lifecycle management. Expert Systems with Applications, 31(1), 3040.

Levitt, T. (1965). EXPLOIT the Product Life Cycle. Harvard Business Review, 43(6), 81-94.

Parlikad, A. K., McFarlane, D., Fleisch, E., \& Gross, S. (2003). The Role of Product Identity in End-of-Life Decision Making [Electronic Version]. Auto-ID Center White Paper from http://www.autoidlabs.org/single-view/dir/article/6/149/page.html.

Patton, A. (1959). Stretch your products' earning years. Management Review, 38(June), 67-79.

Polli, R., \& Cook, V. (1969). VALIDITY OF THE PRODUCT LIFE CYCLE. Journal of Business, 42(4), 385-400.

Potts, G. W. (1988). Exploit your product's service life cycle. Harvard Business Review, September-October, 32-36.

Rink, D. R., Roden, D. M., \& Fox, H. W. (1999). Financial management and planning with the product life cycle concept. Business Horizons, September-October, 65-72.

Rose, C. M., Ishii, K., \& Stevels, A. (2002). Influencing Design to Improve Product End-of-Life Stage Research in Engineering Design, 13(2), 83-93.

Thierry, M., Salomon, M., Van Nunen, J. and Van Wassenhove, L., Strategic issues in product recovery management. California Management Review, 1995, 37 (2), 114.

Thoben, K., Eschenbacher, J., \& Jagdev, H. (2001). Extended Products: Evolving Traditional Product Concepts. Proc. 7th Inter. Conf. on Concurrent Enterprising, 27-29 June, Bremen, Germany.

Vernon, R. (1966). International investment and international trade in the product cycle. Quarterly Journal of Economics, 80(2), 190-207.

Westkaemper, E., Alting, L., \& Arndt, G. (2001a). Life cycle management and assessment: approaches and visions towards sustainable manufacturing. Proceedings of the Institution of Mechanical Engineers Part B, 215(5), 599-626.

Westkaemper, E., Niemann, J., \& Dauensteiner, A. (2001b). Economic and ecological aspects in product life cycle evaluation. Proceedings of the Institution of Mechanical Engineers Part B, 215(5), 673-681.

Wood, L. (1990). The End of the Product Life Cycle? Education Says Goodbye to an Old Friend. Journal of Marketing Management, 6(2), 145-155. 
